\title{
Computation-Motivated Design of Ternary Plasmonic Copper Chalcogenide Nanocrystals
}

Yuan Zeng ${ }^{\dagger, z}$, Paul Hyunggyu Joo ${ }^{\dagger}$ Kesong Yang ${ }^{\dagger, z}$, Andrea R. Tao ${ }^{*, \dagger, z}$

† Department of NanoEnginnering, University of California San Diego, La Jolla, CA 92093-0448, United States

${ }^{\text {Z}}$ Program of Materials Science and Engineering, University of California San Diego, La Jolla, CA 92093-0418, United States 


\section{S1: Reaction Kinetics}

We performed linear fitting for both first order reaction ( $\left.\operatorname{Ln}\left[\mathrm{A}_{0}\right]-\operatorname{Ln}[A]\right)$ and second order reaction $\left(1 / \mathrm{A}-1 / \mathrm{A}_{0}\right)$, the $\mathrm{R}$-square value is 0.866 for first order reaction and 0.917 for second order reaction. Therefore, this anion exchange should be second order reaction
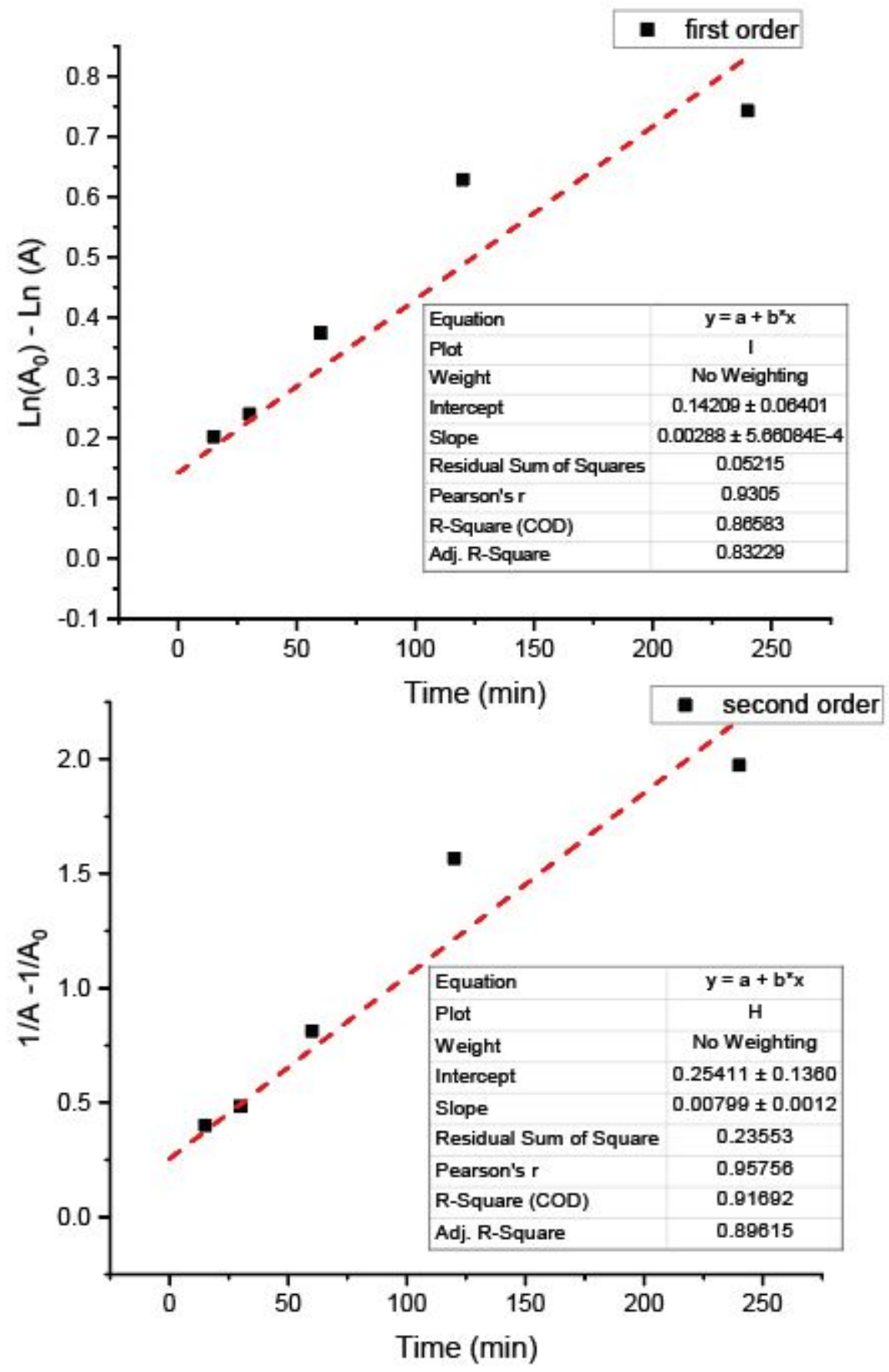
S2: EDS Mapping of Anion Exchanged Alloy

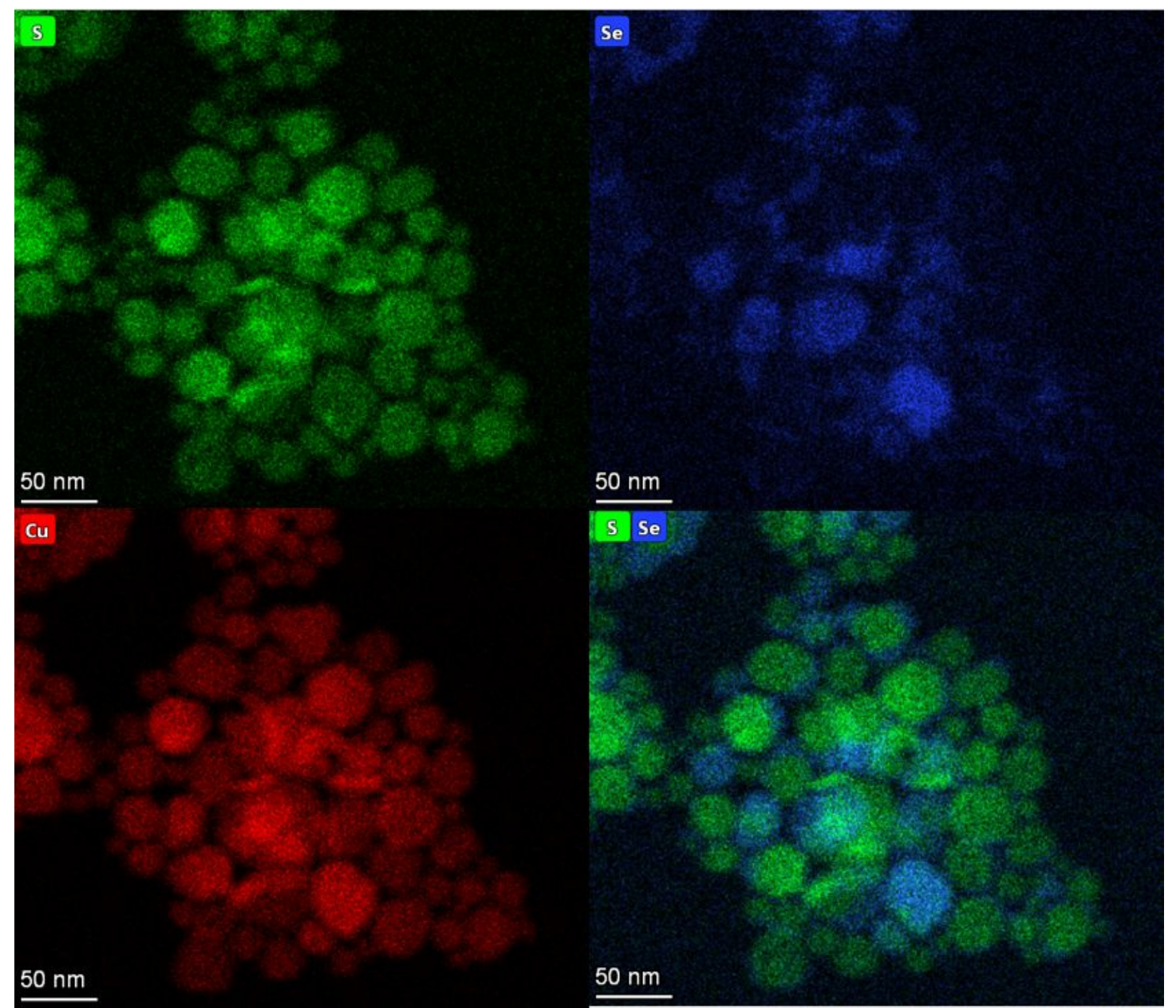




\section{S3: Ligand Exchange Experiment}

The ligand exchange protocol is modified from previous papers ${ }^{1} .0 .5 \mathrm{~mL}$ CuS chloroform solution, $0.5 \mathrm{~mL}$ ethanol and $1 \mathrm{~mL}$ capping ligand were added in a 20 $\mathrm{mL}$ glass vial and stirring 24 hours. Then washed three time with excess chloroform/ethanol mixture, centrifuge at 6k RPM and dispersed in chloroform solution for UV/Vis Characterization.

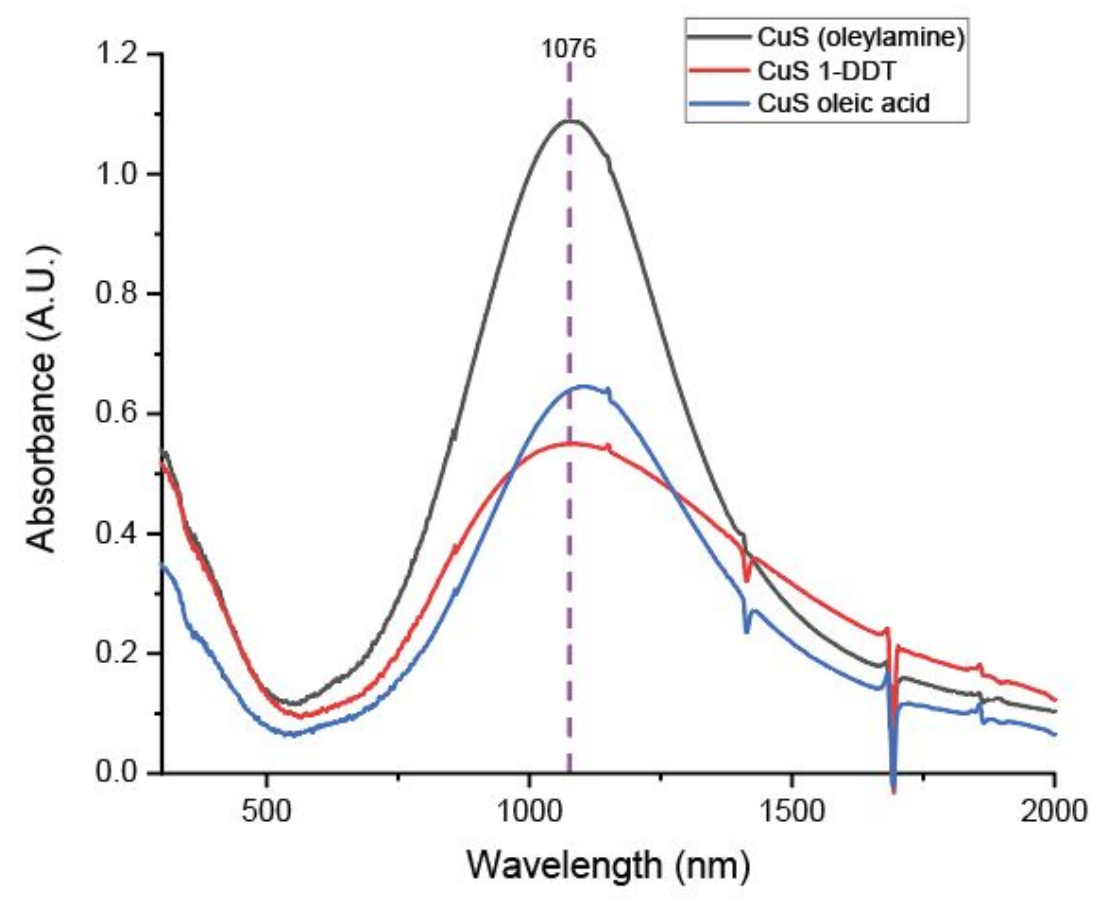

Both oleylamine capped CuS and 1-DDT exchanged CuS has LSPR resonance at 1076 $\mathrm{nm}$ and oleic acid exchanged CuS has LSPR resonance at $1104 \mathrm{~nm}$.

\section{Reference}

(1) Wang, J.; Hsu, S.; Gonzalez-Pech, N.; Jhunjhunwala, A.; Chen, F.; Hariri, A.; Grassian, V.; Tao, A.; Jokerst, J. V. Copper Sulfide Nanodisks and Nanoprisms for Photoacoustic Ovarian Tumor Imaging. Part. Part. Syst. Charact. 2019, 36 (8), 1900171. https://doi.org/10.1002/ppsc.201900171. 